\title{
Distribution of metal contamination and grain size in the sediments of Nakdong River, Korea
}

\author{
Shin Kim $(\mathbb{D} \cdot$ Deuk Seok Yang $\mathbb{D} \cdot$ Yong Seok Kim
}

Received: 2 April 2020 / Accepted: 5 July 2020 /Published online: 9 July 2020

(C) The Author(s) 2020

\begin{abstract}
To assess distribution of metal contamination and grain size in the sediments of Nakdong River (South Korea), surface sediments were collected from 21 sites and analyzed. Within the study area, sand was typically the dominant grain size. However, because of the reduced flow rate and flow velocity, sites adjacent to weirs were composed of relatively fine sediments. A comparison of sediment metal concentrations with sediment quality guidelines proposed by the USA, Canada, and South Korea revealed that sites adjacent to weirs had concentrations that exceeded the standard values. The enrichment factor, index of geo-accumulation, and pollution load index calculation results that the sites adjacent to weirs showed high contamination, with $\mathrm{Cd}$ accounting for the highest contamination levels. The metals in the study area varies due to the effect of fine sediments; therefore, high concentrations of metals accumulated adjacent to weirs where fine sediments were distributed in greater proportions. Furthermore, Cd exhibited the greatest contribution to metal contamination in the study area and the highest contamination levels
\end{abstract}

S. Kim $(\bowtie) \cdot$ D. S. Yang $\cdot$ Y. S. Kim

Nakdong River Environment Research Center, National Institute of Environmental Research, 24-11, Gukgasandan-daero 52-gil, Guji-myeon, Dalseong-gun, Daegu, Republic of Korea e-mail: sinima@korea.kr

D. S. Yang

e-mail: yds7055@korea.kr

Y. S. Kim

e-mail: nierkys@korea.kr were found at NS19 (adjacent to the Haman weir). Thus, the accumulation of fine sediment increased due to the influence of the weirs, thereby increasing the overall amount of metal contamination.

Keywords Nakdong River · Sediment · Grain size · Metal contamination

\section{Introduction}

A river is classified into a mainstream and tributaries, both of which are directly related to human activities. In recent years, the natural purification capability of rivers has decreased and the river environment has gradually deteriorated due to increased residential and industrial sewage and wastewater linked to population growth, improved living standards, and industrial progress (Kim et al. 2015a, b). Furthermore, river environments are largely affected by artificial structures, such as weirs, as well as cities and industrial complexes built adjacent to rivers (Ahn et al. 2014).

Contaminants flowing into a river are discharged to the environment through various paths. Contaminants flowing into the water system typically accumulate in sediments transported and deposited by the flow of water, waves, tidal currents, and wind. Contaminants deposited in rivers or lakes then accumulate on the bottom and influence the river ecosystem. To obtain a complete understanding of the river environment, it is important to analyze the geochemical components (e.g., metals) that accumulate in the sediments as well as the 
water quality environment (Thornton 1983). Water quality analysis is key for understanding the current short-term environmental conditions; however, sediments contain higher metal concentrations and exhibit smaller temporal and spatial changes than waster because of their limited movement. Therefore, river sediments are a useful tool for evaluating continuous environmental effects (Ra et al. 2013). Specifically, metals in sediments always exist in the aquatic environment and have an important influence on benthic organisms. Moreover, they have harmful effects on the hydroecosystem when released into the water and can lead to physical/chemical changes (Alloway et al. 1988; Dekov et al. 1997). Thus, determining the distribution and behavior of chemical components in sediments, including metals, reveals the sediment environment of a river and can be used to provide efficient response measures, such as controls on various environmental factors (Kim et al. 2001).

Previous studies on river sediments in South Korea have involved various analysis methods and evaluations of organic matter and heavy metals inside the sediments, with a particular focus on core and surface sediments (Kim et al. 2010; Park et al. 2011; Kim et al. 2015a, b). In addition, researchers have evaluated contamination levels using the concentration of metals distributed in the sediments. These studies typically assess the contamination level by comparing with the absolute baseline values of sediment quality guidelines (SQGs) derived for each country. Another typical assessment method employs the concentration of metals among crustal materials or in an uncontaminated area as the background concentration for comparison (Sekabira et al. 2010; Kim and Um 2013; Md et al. 2015; Han et al. 2016).

Unlike conventional studies that are performed within a limited spatial area, this study aims to investigate the complete sediment environment of the Nakdong River by determining the grain size distribution and metal contamination in the mainstream and tributaries of the Nakdong River system. Moreover, to assess the contamination level of metals, a comparison is made not only with the SQGs of South Korea but also with those of USA and Canada. Based on the measured metal concentrations, we calculate the EF (enrichment factor), Igeo (index of geo-accumulation), and PLI (pollution load index). Then, by assessing metal contamination at each site, we determine the area with the highest contamination for further analysis. Furthermore, the principal component analysis (PCA) method is used to determine the relationships between each variable and the main factors influencing the contamination level of sediments in the study area. As a result, the objective of this study is to understand distribution of metal contamination and grain size in sediments and provide useful data for future management and contamination assessments of river sediments.

\section{Material and methods}

\section{Study area and sediment sampling}

The study area, i.e., the Nakdong River in South Korea, has the basin area of $23,384.21 \mathrm{~km}^{2}$, a mainstream river length of $400.7 \mathrm{~km}$, and a river length of $510.36 \mathrm{~km}$. It is located in the southeast of South Korea at a longitude and latitude of $127^{\circ} 29^{\prime} 19^{\prime \prime}-129^{\circ} 18^{\prime} 00^{\prime \prime}$ and $34^{\circ} 59^{\prime} 41^{\prime \prime}-37^{\circ}$ $12^{\prime} 52^{\prime \prime}$. It lies adjacent to the Han River basin to the north and the Geum River and Seomjin River basins to the west (Jung et al. 2016). The Taebaek Mountains form the east sea coast basin and watersheds in the east, and the southern sea area of the Nakdong River lies to the south. The administrative areas include three metropolitan cities (Busan, Daegu, and Ulsan Metropolitan Cities) and parts of five provinces (Gyeongsangnam-do, Gyeongsangbuk-do, Jeonlanam-do, Jeonlabuk-do, and Gangwon-do). Furthermore, during the Four River Refurbishment Project, which was conducted in order to control floods and secure water resources that were deemed insufficient for the continuously increasing water demands of recent years, river channels were dredged and a total of 16 multi-purpose weirs were constructed. Of these, eight were built in the Nakdong River (NIER 2017).

This study selected a total of 21 sites in the mainstream and tributaries of the Nakdong River and collected surface sediments from September to November 2016. For the sediment samples, a Ponar grab was used, a type of gravity corer in which the bottom blade closes when the corer touches a basal surface, releasing the tension. Surface sediments were collected in this way from the upper $1-3 \mathrm{~cm}$ of sediments. Among the 21 sites, 11 are located in the mainstream and 10 in the tributaries. Eight of the mainstream sites (NS04, NS07, NS08, NS09, NS10, NS11, NS12, and NS19) are adjacent to weirs (Sangju Weir, Nakdan Weir, Gumi Weir, Chilgok Weir, Gangjeong-Goryeong Weir, Dalseong Weir, Hapcheon-Changnyeong Weir, and Changnyeong-Haman Weir, respectively) (Fig. 1). 


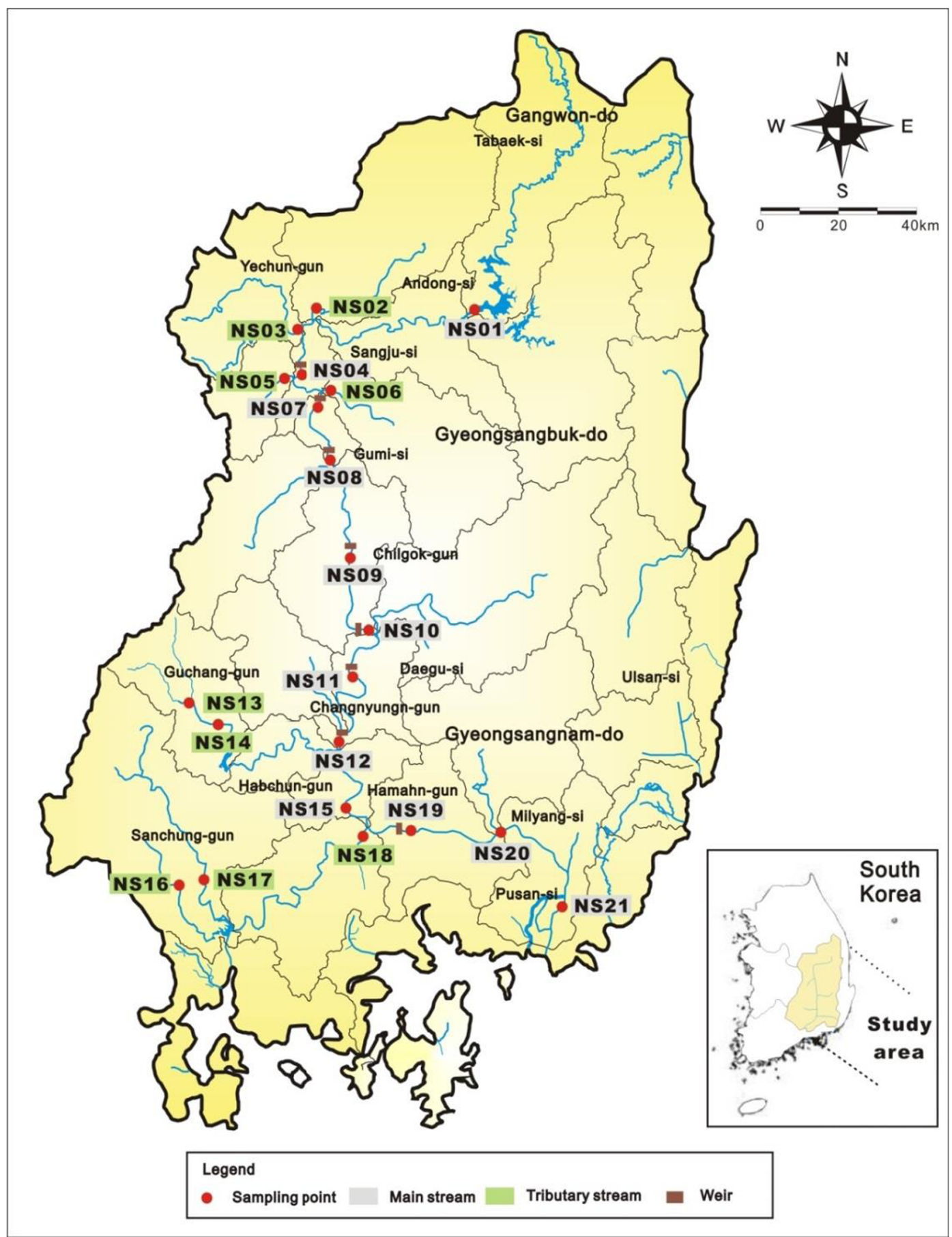

Fig. 1 Location of sampling sites in the study area

Analysis of surface sediments

The samples used for grain size analysis were first collected in plastic bottles and then transported to the laboratory for analysis. For the grain size analysis, a pre- treatment process was performed, which decomposed the organic matter with hydrogen peroxide $\left(\mathrm{H}_{2} \mathrm{O}_{2}\right)$. Subsequently, the grain size was measured by a Microtrac S3500 grain size analyzer that uses the laser diffraction principle and calculates the grain size 
distribution by measuring the difference in diffraction patterns when the sediment grains pass through a laser beam. The measured results were classified into sand, silt, and clay according to the sediment composition. The sand was sub-divided into five sizes: very coarse sand, coarse sand, medium sand, fine sand, and very fine sand. The textural parameters for the sediments, such as mean grain size, sorting, and skewness, were obtained using the method of Folk and Ward (1957) after converting the weight percentage in each grain size class of sediments. To express the grade of grain size, because the logarithmic scale is more useful than the equimultiple scale, $\Phi$ (phi) was used, and the relation between $\Phi$ and grain diameter, $D$, was expressed as $\Phi=$ $-\log _{2} D$ (size in $\mathrm{mm}$ ).

Samples for metal analysis (Al, $\mathrm{Li}, \mathrm{Zn}, \mathrm{Cr}, \mathrm{Pb}, \mathrm{Ni}$, $\mathrm{Cu}$, and $\mathrm{Cd}$ ) in sediments were first mixed onsite at the time of collection using a non-metallic sample spoon and then sieved with a $150-\mu \mathrm{m}$ sieve. Subsequently, samples were placed in glass bottles and stored in a portable cool box and were then transported to the laboratory for analysis. They were then dried in a natural state and crushed to obtain ground powder samples. The powder samples were pre-treated by adding HNO3, $\mathrm{HClO} 4$, and $\mathrm{HF}$ (in a 2:1:2 ratio), and the analysis was performed by an inductively coupled plasma-atomic emission spectrometry (ICP-AES). This analysis method was performed in accordance with the "test standard for sediments of river and lake" one of the "water quality pollution test standards" of the National Institute of Environmental Research of South Korea (Ministry of Environment 2012).

\section{Sediment quality guidelines}

In this study, the metal analysis results were compared with the sediment quality guidelines of USA, Canada, and South Korea (Table 1). The US EPA sediment quality standard is a standard of the Regional Environmental Protection Agency for freshwater sediment contamination classification. According to the content of each metal element ( $\mathrm{Zn}, \mathrm{Pb}, \mathrm{Cu}, \mathrm{Ni}$, and $\mathrm{Cd})$, there are three standard classifications: non-polluted, moderately polluted, and heavily polluted (US EPA 1999). Canada's Ontario sediment guidelines express the adverse effects of sediments on benthic organisms in terms of probability, with three contamination levels: NEL indicates no effect on the organisms living in the sediments, LEL indicates no effect on a large number of organisms living in the sediments, and SEL indicates an adverse effect on benthic organisms (CCME 1995). The National Institute Environmental Research sediment pollution evaluation of South Korea provides four levels of classification for the effects of sediment metal content on benthic organisms. Level I indicates almost no possibility of toxicity appearing in the benthic organisms. Level II indicates a possibility of toxicity, level III indicates a relatively high possibility of toxicity, and level IV indicates a very high possibility of toxicity (NIER 2015).

\section{Calculation methods of EF, Igeo, and PLI}

To evaluate metal contamination in sediments, comparisons are typically made with the metal contents of crustal material or natural concentrations in an uncontaminated area near the study area. These methods can estimate the concentrated amount of measured metal contents by using the difference or proportion of established standard elements and natural metal contents (Kim and Jang 2014). Accordingly, to eliminate the effect of grain size in the sediments, this study used $\mathrm{Al}$, which is a major element in the sediments and exhibits relatively small content variations and a large distribution in the sediments. For the background concentrations, we used the values provided by the River Sediments Background Concentrations of the NIER of South Korea (NIER 2011), which are average concentrations of metals distributed in South Korean river sediments, considering the local characteristics of the study sites. The contamination level was then assessed by calculating the EF, Igeo, and PLI. The EF is calculated by Eq. (1):

$\mathrm{EF}=\left(\frac{M(\text { metal })}{M(\text { reference })}\right)$ sediment $/\left(\frac{M(\text { metal })}{M(\text { reference })}\right)$ reference value (1)

where $(M$ (metal) / $M$ (reference) $)$ sediment is the concentration ratio of the metal to the reference element (Al) in the sediment sample, and where (M(metal) / $\mathrm{M}$ (reference)) reference value refers to the ratio of the metal to the reference element in the background concentration (Bruland et al. 1974). An EF value of 1.5 or less indicates an uncontaminated natural environment, whereas EF greater than 1.5 implies artificial contamination due to inflow through the air and river (Zhang and Liu 2002; Hyun et al. 2007). And Yongming et al. (2006) suggest deficiency to minimal metal enrichment when EF values are lower than 2. 
Table 1 US EPA sediment quality standard, Ontario sediment quality guidelines and NIER sediment pollution evaluation standard (unit: $\mathrm{mg} / \mathrm{kg})$

\begin{tabular}{|c|c|c|c|c|c|c|c|c|c|}
\hline & \multicolumn{3}{|c|}{ US EPA sediment quality standard } & \multicolumn{2}{|c|}{$\begin{array}{l}\text { Ontario sediment quality } \\
\text { guidelines }\end{array}$} & \multicolumn{4}{|c|}{$\begin{array}{l}\text { NIER sediment pollution evaluation } \\
\text { standard }\end{array}$} \\
\hline & Non-polluted & Moderately polluted & Heavily polluted & LEL & SEL & I & II & III & IV \\
\hline $\mathrm{Zn}$ & $<90$ & $90-200$ & $>200$ & 120 & 820 & $\leq 363$ & $\leq 1170$ & $\leq 13,000$ & $>13,000$ \\
\hline $\mathrm{Pb}$ & $<40$ & $40-60$ & $>60$ & 31 & 250 & $\leq 59$ & $\leq 154$ & $\leq 459$ & $>459$ \\
\hline $\mathrm{Cu}$ & $<25$ & $25-50$ & $>50$ & 16 & 110 & $\leq 48$ & $\leq 228$ & $\leq 1890$ & $>1890$ \\
\hline $\mathrm{Cr}$ & - & - & - & - & - & $\leq 112$ & $\leq 224$ & $\leq 991$ & $\leq 991$ \\
\hline $\mathrm{Ni}$ & $<20$ & $20-50$ & $>50$ & 16 & 75 & $\leq 40$ & $\leq 87.5$ & $\leq 330$ & $>330$ \\
\hline $\mathrm{Cd}$ & - & - & $>8.0$ & 0.6 & 10 & $\leq 0.4$ & $\leq 1.87$ & $\leq 6.09$ & $>6.09$ \\
\hline
\end{tabular}

The Igeo shows the relative concentration level of metals. Unlike the load coefficient, it can be used to evaluate the level of contamination by directly grading the contamination level of sediments. Igeo $=0-1$ indicates unpolluted/moderately polluted, $1-2$ indicates moderately polluted, 2-3 indicates moderately polluted/strongly polluted, and $>3$ indicates strongly polluted. Igeo is calculated by Eq. (2), where $M$ (sediment) is the corresponding metal concentration, $M$ (background) is the background concentration of the corresponding metal, and a constant of 1.5 is multiplied for compensation (Muller 1979).

Igeo $=\log _{2} \frac{M(\text { sediment })}{M(\text { background }) \times 1.5}$

The PLI can assess the overall contamination in an area, including all analyzed metals, unlike Igeo and EF. It is calculated by Eq. (3), calculated as a ratio of the metal concentration, $M$ (sediment), and the background concentration of the natural environment state $M$ (background). When PLI is higher than 1, it implies contamination. As the value increases, the contamination level increases (Tomlinson et al. 1980).

PLI

$$
=\sqrt[n]{\left(\frac{M(\text { sediment })}{M(\text { reference })}\right) 1 \times\left(\frac{M(\text { sediment })}{M(\text { reference })}\right) 2 \times \ldots\left(\frac{M(\text { sediment })}{M(\text { reference })}\right) n}
$$

Principal component analysis

Principal component analysis is a statistical analysis method that groups multiple variables with similar common dimensions and reduces them to a relatively small number of factors (Grant 1990). This is the most common multivariate statistical method used in environmental studies to reduce data and extract a small number of latent factors for analyzing relations among the observed variables (Chen et al. 2007). To investigate the relationship between all factors analyzed in this study, grain size analysis (i.e., sediment composition, mean grain size, sorting, and skewness), analysis of the concentration and contamination (i.e., EF, Igeo, and PLI) of metals in the study area, and principal component analysis were conducted using SPSS 20.0 software.

\section{Result and discussion}

Distribution of grain size

According to the grain size analysis results of surface sediments in the study area, sand is the dominant grain size overall (average $88.02 \%$ ). At the majority of sites, the sand content exceeds $90 \%$ with medium sand the most dominant class (average 34.96\%). At sites NS04 $(61.7 \%)$, NS09 (69.1\%), and NS10 (71.9\%), the areas adjacent to weirs constructed in the study area, slightly smaller sand contents are observed compared with other sites. Specifically, site NS07 is predominantly composed of fine-grained sediments, with $27.5 \%$ sand, $60.2 \%$ silt, and $12.1 \%$ clay (Fig. 2). Grain size is significantly influenced by the flow rate and flow velocity (Kim et al. 2017). Indeed, flow velocity changes and temporary stagnation of flowing streams are linked to the riverbed slope and river channel direction changes caused by the installation of artificial structures (Oh et al. 2003). This agrees with our results, whereby finer 


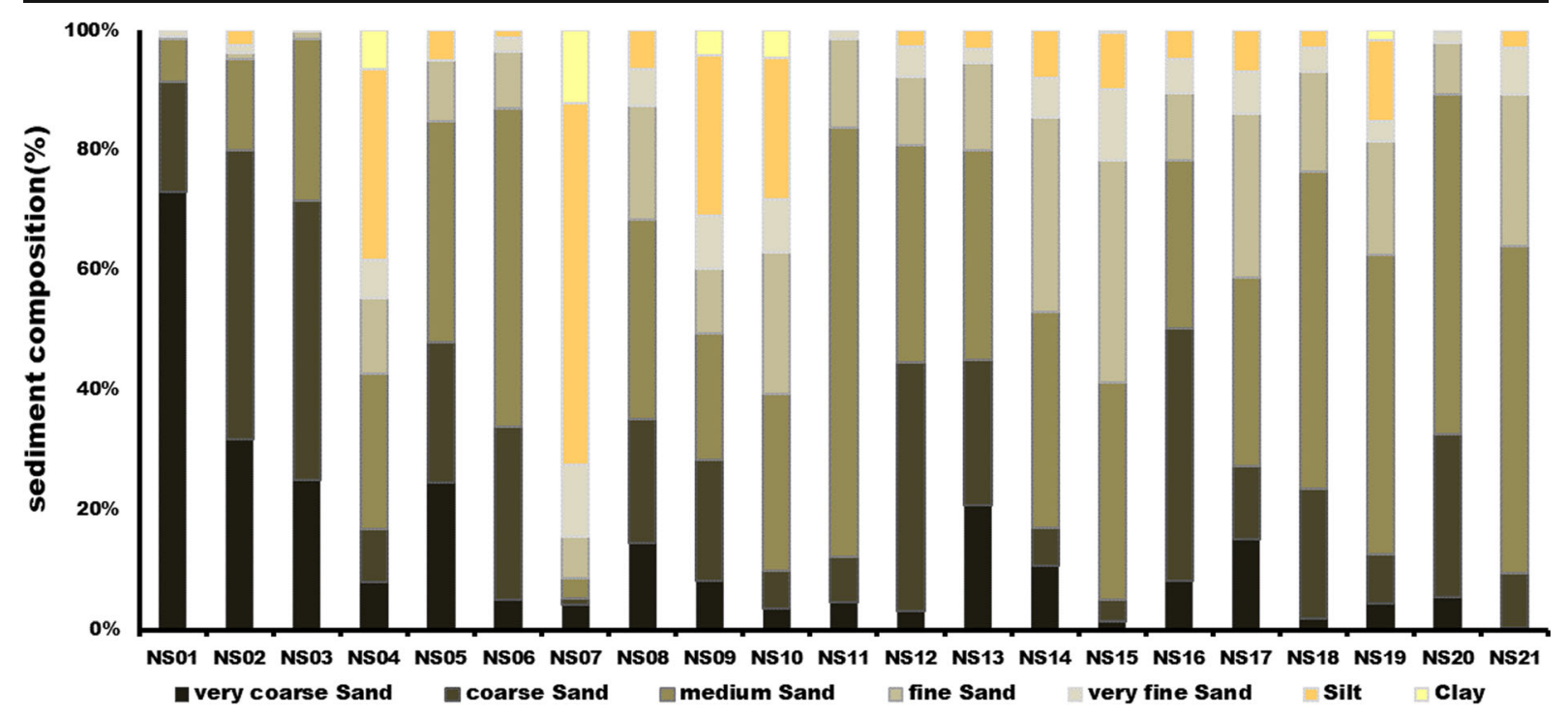

Fig. 2 Sediment composition of surface sediments in the study area

grain sizes are found at sites adjacent to weirs than at other sites because of the effect of decreased flow rate and flow velocity close to the weirs.

The mean grain size is $1.80 \Phi$, which corresponds to medium sand, and the sand grains are predominantly distributed in the ranges of $0-1 \Phi$ (coarse sand) and 1-2 $\Phi$ (medium sand). However, at sites NS04 and NS07, where silt is dominant, the mean grain size is $3.43 \Phi$ and $5.44 \Phi$, respectively, which are finest grain sizes in the study area. Sorting indicates the homogeneity level of grains through a standard deviation of the grains. A value of less than 0.35 indicates very well sorted grains, $0.35-0.5$ $\Phi$ indicates well sorted, $0.5-1 \Phi$ indicates moderately well sorted, $0.7-1.0 \Phi$ indicates moderately sorted, $1-2 \Phi$ indicates poorly sorted, $2-4 \Phi$ indicates very poorly sorted, and above $4 \Phi$ indicates extremely poorly sorted. The average value for the study area is $1.40 \Phi$, which corresponds to poorly sorted grains. In general, grains are moderated sorted and poorly sorted, whereas sites NS04, NS09, and NS10 correspond to very poorly sorted grains. Skewness shows the asymmetry of grain distributions and indicates the existence or non-existence of coarse and fine fractions. As the skewness approaches 0 , coarse and fine sediments are distributed more symmetrically. The average value is 0.16 for the study area, and positive values are observed at all sites except for six that exhibit negative values (Fig. 3).

The textural parameters derived from the grain size analysis reflect the energy conditions in the sedimentation environment. In a low-energy environment, the sediments are fine, sorting is poor, and positive skewness is shown. Conversely, in a high-energy environment, coarse sediments with good sorting tend to show positive or negative skewness (Kim et al. 2018). Furthermore, a large positive value of skewness indicates dominant erosion due to physical effects such as flow velocity. On the other hand, when the skewness is small, the area can be classified as one where sedimentation is dominant because the physical effects are relatively weak (Folk 1980). In other words, the very high silt content adjacent to the weirs in the study area, as well as the poor sorting and low skewness, indicates a reduced flow rate and flow velocity, which can have large effects on the transport of sediments, thereby indicating a low-energy environment where sedimentation is active.

Contamination and concentration of metal

The concentrations of the eight analyzed metals ( $\mathrm{Al}, \mathrm{Li}$, $\mathrm{Zn}, \mathrm{Pb}, \mathrm{Cu}, \mathrm{Cr}, \mathrm{Ni}$, and $\mathrm{Cd}$ ) are shown in Table 2. The average concentration of $\mathrm{Al}$ is $6.9 \%$ and exceeds $8 \%$ at four sites. The average concentration of $\mathrm{Li}$ is $25.6 \mathrm{mg} / \mathrm{kg}$, exceeding $40 \mathrm{mg} / \mathrm{kg}$ at three sites. The average concentration of $\mathrm{Zn}$ is $120.2 \mathrm{mg} / \mathrm{kg}$ and exceeds $200 \mathrm{mg} / \mathrm{kg}$ at NS09 and NS19. The average concentration of $\mathrm{Cr}$ is $48.5 \mathrm{mg} / \mathrm{kg}$ and is highest at site NS19 $(83.6 \mathrm{mg} / \mathrm{kg})$. The average concentrations of $\mathrm{Pb}$ and $\mathrm{Cu}$ are $24.6 \mathrm{mg} / \mathrm{kg}$ and $16.9 \mathrm{mg} / \mathrm{kg}$, respectively. The highest concentrations of $\mathrm{Pb}$ (over $40 \mathrm{mg} / \mathrm{kg}$ ) and $\mathrm{Cu}(43.3 . \mathrm{mg} / \mathrm{kg}$ ) are 

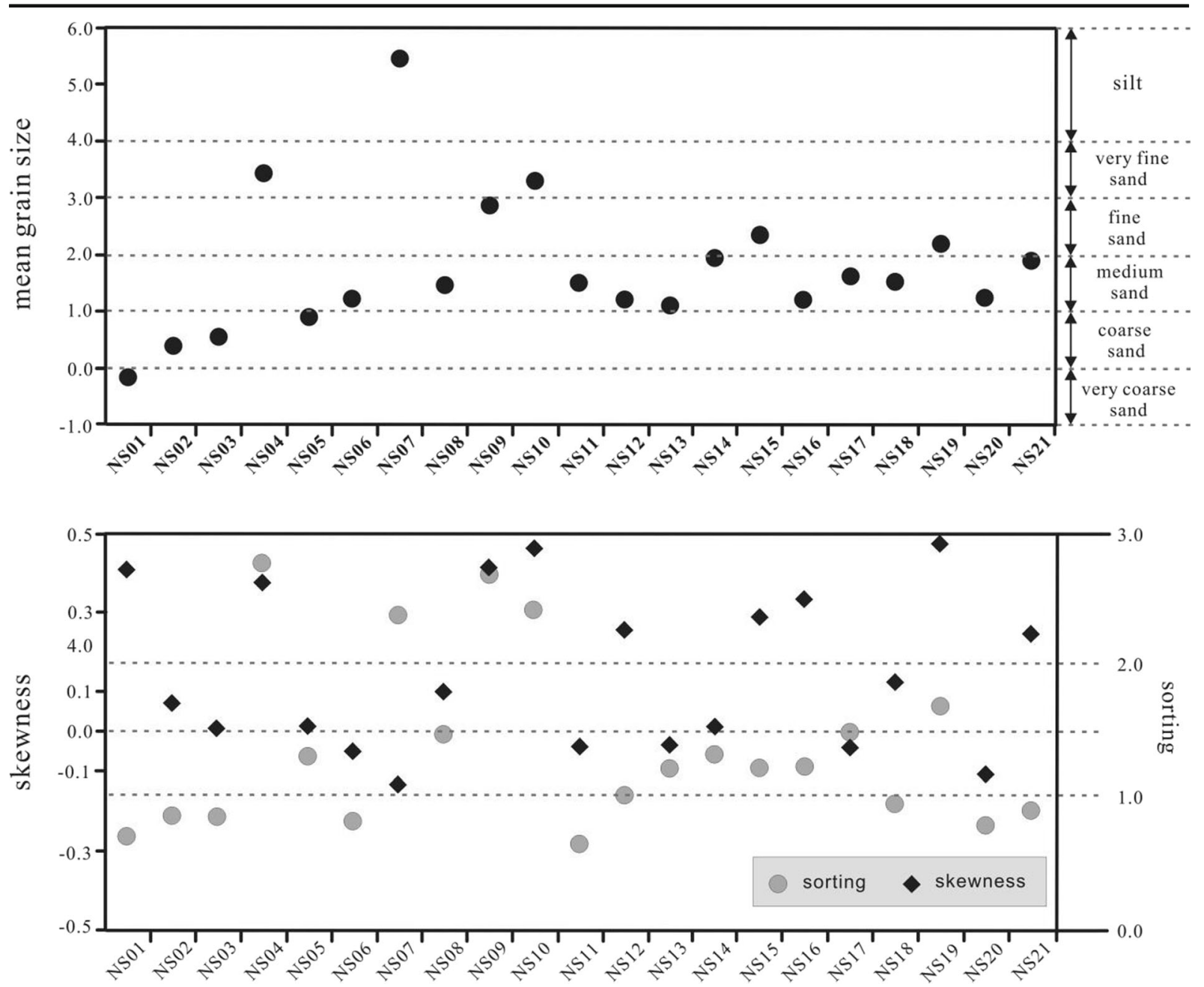

Fig. 3 Mean grain size, sorting, and skewness of surface sediments in the study area

observed at site NS19, respectively. The average concentrations of $\mathrm{Ni}$ and $\mathrm{Cd}$ are $16.08 \mathrm{mg} / \mathrm{kg}$ and $0.38 \mathrm{mg} / \mathrm{kg}$, respectively, and their maximum concentration is observed at site NS19.

Table 3 presents the comparison of the sediment metal concentration results of the study area (i.e., Nakdong River) with the results of Korea's other three major rivers: Han River, Geum River, and Yeongsan River. As shown in the table, the metal concentrations in the sediments of the Nakdong River, i.e., all study sites for this investigation, showed similar results as the metal concentrations observed in the Geum River (Lee et al. 2014) and Yeongsan River (Shin et al. 2015). However, sediments of the Han River, which lies more closely adjacent to urban areas in comparison with the other rivers, showed relatively high metal concentrations, including $\mathrm{Pb}$ and $\mathrm{Cu}$, demonstrating high pollution by these contaminants (Lai et al. 2013). Additionally, metal concentrations of river sediments found in other countries, such as China, India, and Australia, generally showed higher concentration distributions in comparison with this study area. In particular, the Ganga River of India can be seen to have significantly higher concentrations in comparison with the Nakdong River due to the effects of domestic, industrial, and agricultural untreated wastewater (Song et al. 2011; Duodu et al. 2016; Pandey et al. 2014). As such, it can be inferred that the sediments found in the Nakdong River showed lower metal concentrations in comparison with other river sediments due to the lesser amount of anthropogenic impacts due to domestic, industrial, and agricultural environmental factors.

Table 4 shows the comparison of metal concentrations in the study area with the US EPA sediment quality 
Table 2 Metal concentrations of surface sediments in the study area

\begin{tabular}{|c|c|c|c|c|c|c|c|c|}
\hline & $\mathrm{Al}(\%)$ & $\mathrm{Li}(\mathrm{mg} / \mathrm{kg})$ & $\mathrm{Zn}(\mathrm{mg} / \mathrm{kg})$ & $\mathrm{Cr}(\mathrm{mg} / \mathrm{kg})$ & $\mathrm{Pb}(\mathrm{mg} / \mathrm{kg})$ & $\mathrm{Cu}(\mathrm{mg} / \mathrm{kg})$ & $\mathrm{Ni}(\mathrm{mg} / \mathrm{kg})$ & $\mathrm{Cd}(\mathrm{mg} / \mathrm{kg})$ \\
\hline NS01 & 7.98 & 12.0 & 160.0 & 11.6 & 14.8 & 11.4 & 8.0 & 0.72 \\
\hline NS02 & 7.29 & 22.2 & 82.2 & 12.4 & 23.0 & 10.5 & 10.2 & 0.12 \\
\hline NS03 & 4.62 & 21.9 & 64.3 & 36.3 & 20.8 & 9.2 & 12.6 & 0.17 \\
\hline NS04 & 7.70 & 29.2 & 118.5 & 44.3 & 25.4 & 37.9 & 17.5 & 0.36 \\
\hline NS05 & 4.79 & 11.6 & 67.0 & 29.5 & 18.2 & 9.5 & 10.0 & 0.19 \\
\hline NS06 & 4.74 & 20.7 & 49.0 & 52.1 & 18.0 & 8.5 & 11.6 & 0.32 \\
\hline NS07 & 6.76 & 42.3 & 145.3 & 55.8 & 30.4 & 25.3 & 27.0 & 0.39 \\
\hline NS08 & 7.34 & 36.0 & 137.1 & 50.5 & 27.2 & 19.7 & 20.9 & 0.39 \\
\hline NS09 & 6.39 & 42.1 & 217.1 & 51.8 & 31.9 & 29.4 & 28.3 & 0.42 \\
\hline NS10 & 8.54 & 30.9 & 120.4 & 50.5 & 26.6 & 18.2 & 19.0 & 0.46 \\
\hline NS11 & 4.17 & 17.2 & 81.6 & 62.4 & 23.8 & 13.7 & 11.2 & 0.53 \\
\hline NS12 & 5.23 & 19.3 & 75.6 & 49.2 & 22.5 & 10.9 & 12.1 & 0.52 \\
\hline NS13 & 8.14 & 21.2 & 87.6 & 23.6 & 22.5 & 8.5 & 4.8 & 0.26 \\
\hline NS14 & 7.13 & 28.6 & 151.4 & 29.2 & 23.8 & 13.9 & 8.2 & 0.22 \\
\hline NS15 & 5.71 & 24.7 & 120.4 & 62.6 & 22.3 & 13.3 & 15.7 & 0.36 \\
\hline NS16 & 8.30 & 17.8 & 86.0 & 72.5 & 17.6 & 10.2 & 17.5 & 0.34 \\
\hline NS17 & 8.06 & 25.6 & 127.7 & 79.9 & 24.4 & 20.7 & 26.3 & 0.34 \\
\hline NS18 & 7.17 & 19.6 & 62.1 & 61.6 & 18.7 & 9.8 & 13.9 & 0.29 \\
\hline NS19 & 8.25 & 43.9 & 213.1 & 83.6 & 35.5 & 43.3 & 32.4 & 0.51 \\
\hline NS20 & 6.97 & 22.4 & 95.9 & 56.9 & 25.6 & 8.5 & 13.5 & 0.45 \\
\hline NS21 & 7.61 & 26.7 & 126.7 & 28.0 & 28.0 & 12.2 & 15.3 & 0.40 \\
\hline
\end{tabular}

standards, Canada's Ontario sediment guidelines, and South Korea's NIER sediment pollution evaluations. According to the US EPA sediment quality standard, ten and two sites are moderately polluted with $\mathrm{Zn}$ and $\mathrm{Pb}$, respectively. Moreover, sites NS09 and NS09 are heavily polluted for $\mathrm{Zn}$ and $\mathrm{Pb}$, respectively. With respect to $\mathrm{Cu}$ and $\mathrm{Ni}$, no sites are heavily polluted, but six and ten sites are moderately polluted, respectively. According to the Ontario sediment guidelines, one, five, and seven sites correspond to $\mathrm{LEL}$ for $\mathrm{Zn}, \mathrm{Pb}$, and $\mathrm{Cu}$, respectively. Furthermore, for $\mathrm{Cr}$, all sites excluding the four positions corresponding to NEL correspond to LEL. For Ni, 13 sites correspond to LEL. For Cd, all sites excluding NS01 correspond to NEL. According to the NIER sediment pollution evaluation, the majority of positions correspond to level I, which is an unpolluted level. However, at site $\mathrm{NS} 09, \mathrm{~Pb}$ corresponds to level II, and at four sites (NS01, NS07, and NS08), Cd corresponds to level II, which is the highest contamination level among all the metals. In the comparative analysis with the SQGs of three countries, the majority of metal contents indicate high contamination levels at sites adjacent to weirs.
The EF calculation of surface sediments in the study area reveals $\mathrm{Pb}, \mathrm{Zn}, \mathrm{Cu}, \mathrm{Cr}$, and $\mathrm{Ni}$ values of less than 1.5 at all sites, indicating no anthropogenic contamination and minimal metal enrichment. However, Zn relatively higher contamination at site NS09 (1.30), adjacent to the Chilgok Weir. Moreover, $\mathrm{Cr}$ values are relatively higher at four sites, and $\mathrm{Cd}$, the metal with the highest EF values, exhibits values over 1.5 at all except NS01, NS12, and NS13 (adjacent to the weir), indicating that anthropogenic contamination is pervasive. These results imply that, in general, contamination is relatively high and large impacts in weir-constructed areas. Among all metals, contamination by $\mathrm{Cd}$ is the highest (Fig. 4).

The Igeo value for $\mathrm{Cd}$ is 0.26 at site NS01, which corresponds to partially unpolluted/moderately polluted. Besides this, no other metals or sites exceed Igeo $=0$, indicating that the contamination level is practically unpolluted. However, in the calculation results, $\mathrm{Zn}$ exhibits relatively high values at sites NS09 $(-0.57)$ and NS22 (-0.34), and $\mathrm{Cu}$ and $\mathrm{Cr}$ exhibit relatively high values ( -0.60 and -0.58 , respectively) at site NS19. Because these results show similar trends to the EF 
Table 3 Comparison of different metal concentrations in surface sediments in this study and other studies

\begin{tabular}{|c|c|c|c|c|c|c|c|c|}
\hline Location & Nation & Reference & $\mathrm{Zn}(\mathrm{mg} / \mathrm{kg})$ & $\mathrm{Cr}(\mathrm{mg} / \mathrm{kg})$ & $\mathrm{Pb}(\mathrm{mg} / \mathrm{kg})$ & $\mathrm{Cu}(\mathrm{mg} / \mathrm{kg})$ & $\mathrm{Ni}(\mathrm{mg} / \mathrm{kg})$ & $\mathrm{Cd}(\mathrm{mg} / \mathrm{kg})$ \\
\hline Nakdong River & South Korea & This study & $49.0-217.0$ & $11.6-83.6$ & $14.8-35.5$ & $8.5-43.3$ & $4.8-32.4$ & $0.12-0.72$ \\
\hline Han River & South Korea & Lai et al. (2013) & $52.1-690.7$ & $27.3-146.8$ & $17.1-106.2$ & $5.1-158.5$ & $8.8-57.5$ & $0.05-1.32$ \\
\hline Geum River & South Korea & Lee et al. (2014) & $57.5-124.9$ & $37.6-78.6$ & $8.3-19.4$ & $11.8-22.4$ & 9.9-20.9 & $0.05-0.18$ \\
\hline Yongsan River & South Korea & Shin et al. (2015) & $22-167$ & $2-72$ & $14-40$ & $2-26$ & $3-35$ & $0.01-0.09$ \\
\hline Brisbane River & Australia & Duodu et al. (2016) & $142-257$ & $82-332$ & $25-126$ & $20-110$ & $20-34$ & $0.6-0.9$ \\
\hline Chanjiang River & China & Song et al. (2015) & $50.6-221.0$ & $64.5-126.7$ & $19.0-173.2$ & $10.8-87.9$ & $24.2-52.6$ & $0.35-16.45$ \\
\hline Ganga River & India & Pandey et al. (2014) & 137.3-201.2 & $126.8-196.1$ & $148.8-211.4$ & $12.7-84.0$ & $14.6-82.5$ & $9.5-79.0$ \\
\hline
\end{tabular}

results, we confirm that relatively high contamination appears at sites adjacent to weirs (Fig. 5).

According to the calculation results of EF and Igeo values, $\mathrm{Cd}$ was found to be relatively higher than other metals, indicating a state of higher pollution. Ganugapenta et al. (2018) previously suggested that the high contamination degree of $\mathrm{Cd}$ is generally attributed to agricultural runoff, industrial activities, and other anthropogenic inputs. Additionally, the official Group of Experts on the Scientific Aspects of Marine Pollution (GESAMP) ( 1985) proposed that the contamination degree of Cd may also increase due to influential factors, such as agricultural soils, mining waste, and municipal sewage effluents and sludges. Accordingly, it was assumed that $\mathrm{Cd}$ in sediments found in the NS01 (not adjacent to weirs) showed a relatively high contamination ( $\mathrm{EF}>1.5$, and Igeo $>0$ ) degree due to anthropogenic impacts. Therefore, additional studies should be conducted to explore detailed causes affecting the $\mathrm{Cd}$ concentration levels of sediments observed in the Nakdong River.
Unlike the contamination assessments performed using EF and Igeo, the PLI value can be used to identify the total contamination level by using the concentrations of all analyzed metals. All PLI values for all sites in the study area are less than 1, indicating significantly low contamination. Furthermore, referring to the findings of one study, which suggested that the area with contaminated river sediments (PLI > 1) was influenced by metal pollutants from nearby mines, cities, and industrial activities (Ahn et al. 2019), the PLI value of the present study area was shown to be considerably low, indicating that for this area, the anthropogenic impacts on metals induced by nearby areas were relatively small. However, PLI values also indicate relatively high contamination at the sites NS04, NS07, NS08, NS09, and NS19, which are located in the weir sections. Among these sites, metal contamination is highest at site NS19 (PLI $=0.95)$, located at Haman Weir (Fig. 6).

Table 4 Evaluation for sediment quality guidelines (SQGs) using US EPA, Ontario of Canada, and NIER of Korea

\begin{tabular}{lll}
\hline SQGs & & Site name (metal) \\
\hline US EPA & Non-polluted & Other sites (metals) \\
& Moderately polluted & NS01, 03, 10, 14, 15 (Zn), NS08 (Zn, Ni), NS07, 08, 09, 17, \\
& Heavy polluted & N/D \\
NEL & Other sites (metals) \\
Ontario of Canada & LEL & NS14, 15 (Zn), NS16 (Ni), NS01 (Zn, Cd), NS03 (Cu, Ni), NS07, \\
& & $08,10,17(\mathrm{Zn}, \mathrm{Cu}, \mathrm{Ni}), \mathrm{NS} 09,19,21(\mathrm{Zn}, \mathrm{Pb}, \mathrm{Cu}, \mathrm{Ni})$ \\
& SEL & $\mathrm{N} / \mathrm{D}$ \\
NIER of Korea & Other sites (metals) \\
& Il level & NS01, 09, 10, 19, 20 (Cd) \\
& III level & N/D \\
& IV level & N/D \\
\hline
\end{tabular}




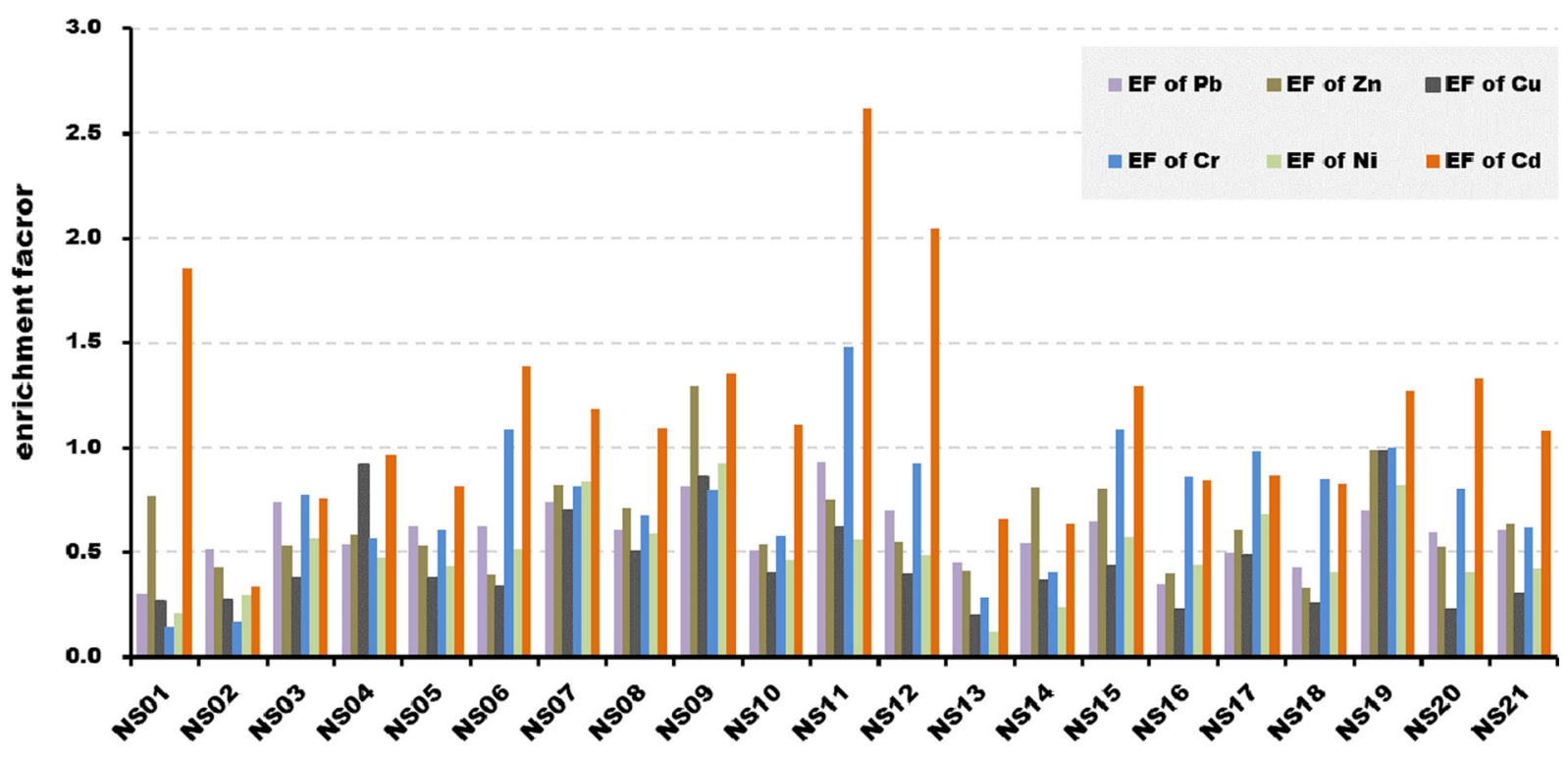

Fig. 4 Enrichment factors of the metals of surface sediments in the study area

Principal component analysis

The principal component analysis was performed using the EF, Igeo, and PLI calculation results, which were employed in the grain size, metal concentration, and contamination assessment, as the factors analyzed in this study. As a result, two principal components were extracted. In the principal analysis results, the eigenvalue, which indicates how much each factor explains the information of existing variables, is $46.08 \%$ for factor 1 and $15.08 \%$ for factor 2 .
The factors corresponding to factor 1 , which have the largest effect on the sediment environment of the study area, are PLI, $\mathrm{Zn}, \mathrm{Pb}, \mathrm{Cu}$, and $\mathrm{Ni}$, EF, Igeo, fine sediments such as very fine sand, silt, and clay, and mean grain size (Table 5). In the component diagram that visualizes the principal components, $\mathrm{Zn}, \mathrm{Pb}, \mathrm{Cu}$, and $\mathrm{Ni}$, which are the metals that have no effect on metal contamination, are concentrated on the right-hand side of the diagram, indicating the assessment result of fine sediments corresponding to factor 1, PLI (overall contamination of the site), and contamination. Therefore, it

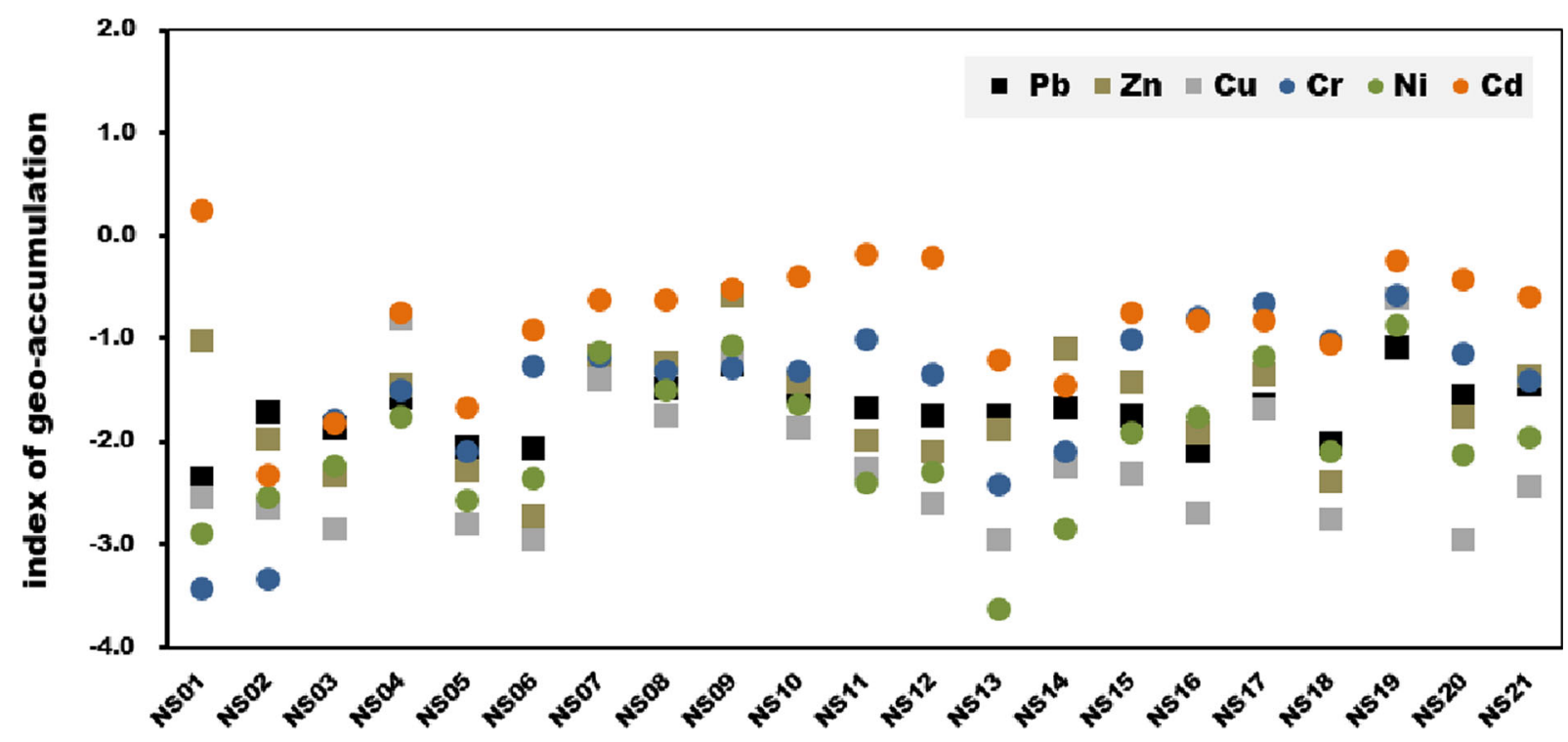

Fig. 5 Index of geo-accumulations of metals of surface sediments in the study area 


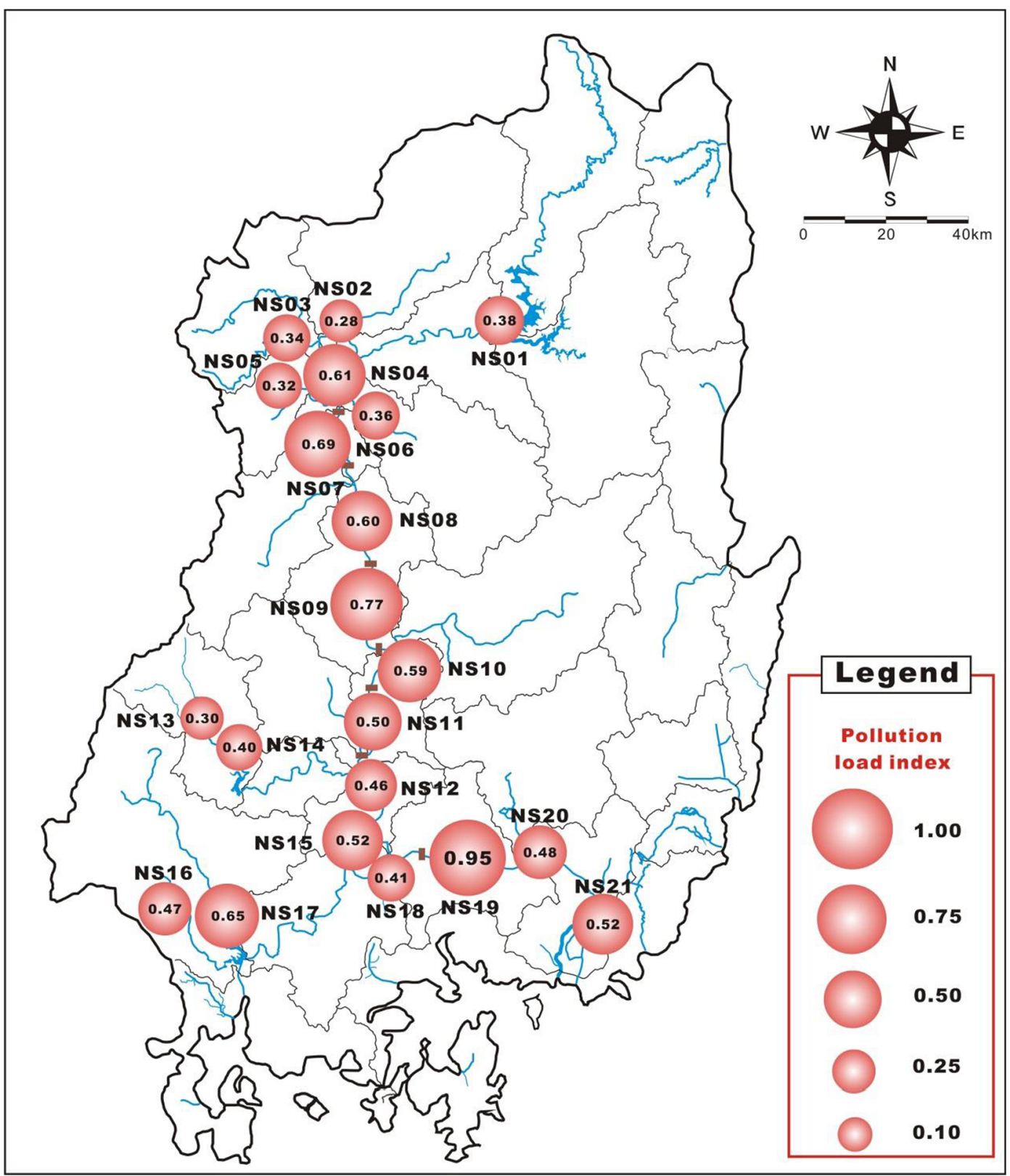

Fig. 6 Pollution load index of surface sediments in the study area

was determined that grain size has a large influence on these four metals. Furthermore, coarse sediments (very coarse sand, coarse sand, and medium sand) have a small effect on contamination. However, as the concentrations of $\mathrm{Cd}$ have a relatively weak relationship with the main factor, fine sand, it is determined that $\mathrm{Cd}$ has a strong influence on metal contamination in the study area (Fig. 7).

The factors that have large correlation coefficients generally exhibit close relationships with geochemical or environmental characteristics. As sediment grains become finer, the surface area becomes larger. Consequently, more matter can be adsorbed, and the increase in ion exchange facilitates the adsorption of metals and organic matter (Horowitz 1991). Therefore, we suggest that the study area is predominantly affected by fine sediments. Moreover, because of flow rate and flow velocity effects, metal concentrations and contamination are relatively high at sites adjacent to the weirs, which 
Table 5 Component matrix (factors 1 and 2) and eigenvalue loading of surface sediments in the study area (principal component analysis)

\begin{tabular}{|c|c|c|c|c|c|c|c|c|c|c|c|c|c|c|c|}
\hline Units & & $\begin{array}{l}\text { Factor } \\
1\end{array}$ & $\begin{array}{l}\text { Factor } \\
2\end{array}$ & \multicolumn{2}{|l|}{ Units } & $\begin{array}{l}\text { Factor } \\
1\end{array}$ & $\begin{array}{l}\text { Factor } \\
2\end{array}$ & \multicolumn{2}{|c|}{ Units } & \multirow{2}{*}{$\begin{array}{l}\text { Factor } \\
1 \\
0.752\end{array}$} & \multirow{2}{*}{$\begin{array}{l}\begin{array}{l}\text { Factor } \\
2\end{array} \\
-0.172\end{array}$} & \multicolumn{2}{|l|}{ Units } & \multirow{2}{*}{$\begin{array}{l}\begin{array}{l}\text { Factor } \\
1\end{array} \\
0.772\end{array}$} & \multirow{2}{*}{$\begin{array}{l}\text { Factor } \\
2 \\
-0.437\end{array}$} \\
\hline $\begin{array}{l}\text { Grain } \\
\text { size }\end{array}$ & $\begin{array}{l}\text { Very coarse } \\
\text { sand }\end{array}$ & -0.465 & -0.621 & Metals & $\mathrm{Al}$ & 0.291 & -0.575 & $\mathrm{EF}$ & $\mathrm{Zn}$ & & & Igeo & $\mathrm{Zn}$ & & \\
\hline & Coarse sand & -0.631 & -0.002 & & $\mathrm{Li}$ & 0.859 & -0.083 & & $\mathrm{Cr}$ & 0.266 & 0.929 & & $\mathrm{Cr}$ & 0.541 & 0.740 \\
\hline & Medium sand & -0.145 & 0.785 & & $\mathrm{Zn}$ & 0.777 & -0.392 & & $\mathrm{~Pb}$ & 0.484 & 0.444 & & $\mathrm{~Pb}$ & 0.832 & -0.025 \\
\hline & Fine sand & 0.345 & 0.224 & & $\mathrm{Cr}$ & 0.526 & 0.690 & & $\mathrm{Cu}$ & 0.855 & 0.021 & & $\mathrm{Cu}$ & 0.923 & -0.186 \\
\hline & Very fine sand & 0.726 & -0.110 & & $\mathrm{~Pb}$ & 0.844 & -0.072 & & $\mathrm{Ni}$ & 0.757 & 0.365 & & $\mathrm{Ni}$ & 0.828 & 0.201 \\
\hline & Silt & 0.736 & -0.275 & & $\mathrm{Cu}$ & 0.879 & -0.169 & & $\mathrm{Cd}$ & 0.184 & 0.434 & & $\mathrm{Cd}$ & 0.497 & 0.149 \\
\hline & $\begin{array}{l}\text { Clay } \\
\text { Mz }\end{array}$ & $\begin{array}{l}0.657 \\
0.805\end{array}$ & $\begin{array}{l}-0.257 \\
-0.023\end{array}$ & & $\begin{array}{l}\mathrm{Ni} \\
\mathrm{Cd}\end{array}$ & $\begin{array}{l}0.864 \\
0.395\end{array}$ & $\begin{array}{l}0.112 \\
0.022\end{array}$ & \multirow{2}{*}{\multicolumn{2}{|c|}{ PLI }} & \multirow[t]{2}{*}{0.963} & \multirow[t]{2}{*}{0.072} & \multirow{2}{*}{\multicolumn{2}{|c|}{$\begin{array}{c}\text { Eigenvalue } \\
\text { loading }\end{array}$}} & \multirow[t]{2}{*}{$46.08 \%$} & \multirow[t]{2}{*}{$15.08 \%$} \\
\hline & $\begin{array}{l}\text { So } \\
\text { Sk }\end{array}$ & $\begin{array}{l}0.785 \\
0.420\end{array}$ & $\begin{array}{l}-0.334 \\
-0.296\end{array}$ & - & & & & & & & & & & & \\
\hline
\end{tabular}

are composed of fine sediments. And the highest contamination levels were found at NS19 (adjacent to the Haman weir). Therefore, structures such as artificially constructed weirs are thought to be the major factor that affect grain size distribution and control the contamination of metals in the sediments of this study area.

\section{Conclusions}

In order to understand the contamination environment of surface sediments in the entire Nakdong River system, surface sediments were collected from 21 sites in the mainstream and tributaries of Nakdong River, South

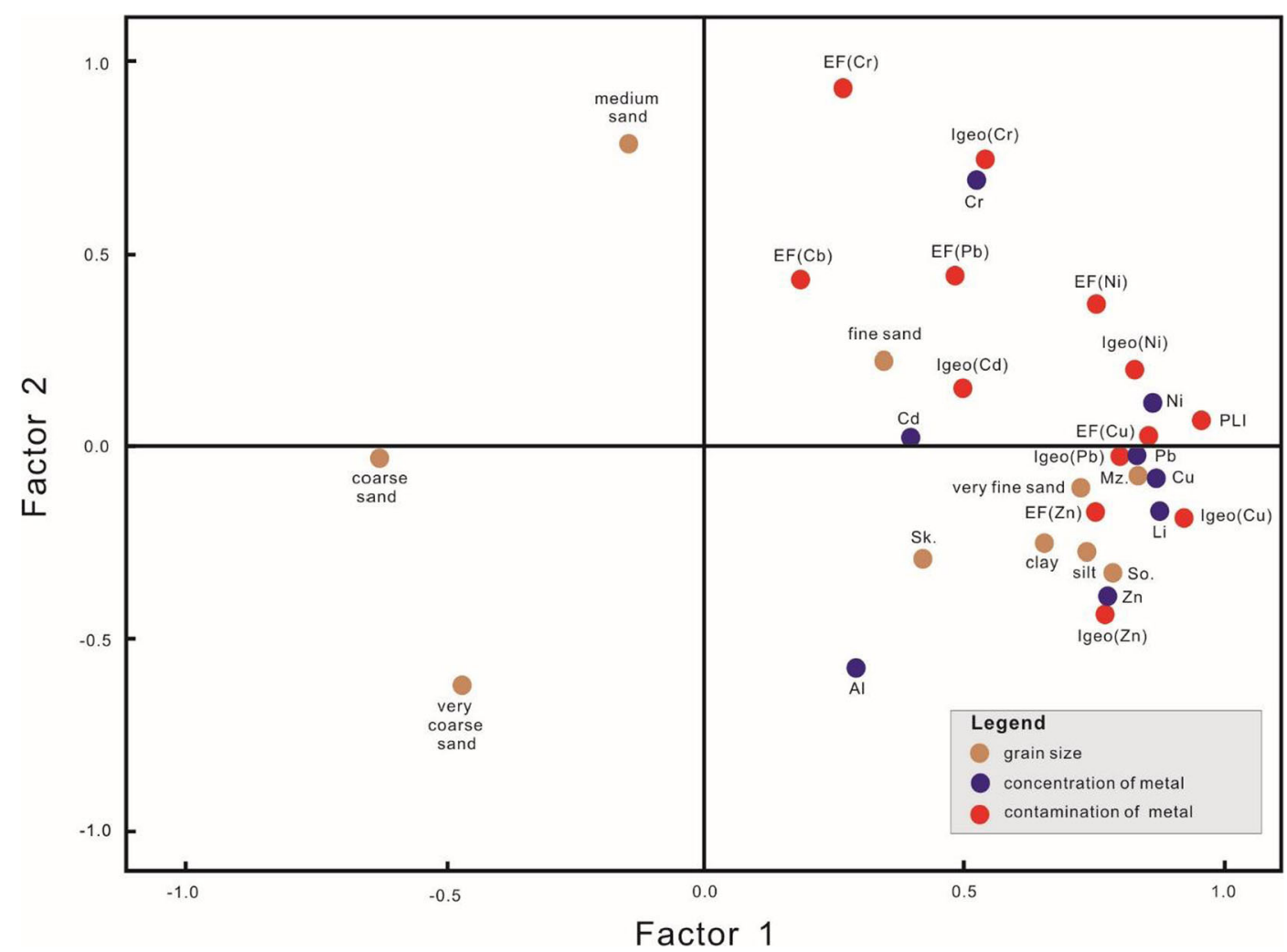

Fig. 7 Plot of principal component analysis of surface sediments in the study area 
Korea. Through a grain size analysis of the collected surface sediments, the sediment composition, mean grain size, sorting, and skewness were obtained. Moreover, the contamination was assessed by analyzing the metal concentration in the sediments, comparing it with the SQGs of different countries, and calculating the EF, Igeo, and PLI values.

In the study area, sand was the dominant grain size; yet, sites adjacent to weirs were composed of relatively fine sediments. This indicated that fine sediments are deposited due to the reduced flow rate and flow velocity around weirs. A comparison of the metal concentrations with the SQGs of USA, Canada, and Korea revealed that contamination exceeded the standard concentrations at sites adjacent to weirs. EF and Igeo values also showed high levels of contamination at sites adjacent to weirs, with $\mathrm{Cd}$ contamination the highest. Furthermore, PLI values revealed that the highest contamination of all weir-adjacent sites occurred at site NS19, located at Haman weir.

In conclusion, anthropogenic contamination in surface sediments of the study area is extremely low, and findings revealed that metal contamination levels are influenced by the effect of fine sediments. Moreover, metal concentrations tend to accumulate substantially at sites adjacent to weirs, where fine sediments are actively deposited because of reduced flow rate and flow velocity. Among the metals, $\mathrm{Cd}$ concentrations exhibited a weak relationship with fine sediment content and demonstrated the greatest effect on metal contamination in the study area. Furthermore, the highest contamination by metals occurred at site NS19, which is located adjacent to the Haman Weir. Thus, the overall accumulation of fine sediments increased due to the influence of weirs, thereby increasing pollution by metal contamination in sediments of the study area.

Acknowledgments The Nakdong River Environment Research Center, National Institute of Environmental Research of Korea, provided all necessary support for the research.

Authors' contributions All authors contributed to the study conception and design. Material preparation, data collection and analysis were performed by Yong Seok Kim, Deuk Seok Yang, and Shin Kim. The first draft of the manuscript was written by Shin Kim and all authors commented on previous versions of the manuscript. All authors read and approve the final manuscript.

Funding information This research was supported by a grant from the National Institute of Environmental Research of Korea (NIER-2019-01-01-078).

\section{Compliance with ethical standards}

Conflict of interest The authors declare that they have no conflict of interest.

Open Access This article is licensed under a Creative Commons Attribution 4.0 International License, which permits use, sharing, adaptation, distribution and reproduction in any medium or format, as long as you give appropriate credit to the original author(s) and the source, provide a link to the Creative Commons licence, and indicate if changes were made. The images or other third party material in this article are included in the article's Creative Commons licence, unless indicated otherwise in a credit line to the material. If material is not included in the article's Creative Commons licence and your intended use is not permitted by statutory regulation or exceeds the permitted use, you will need to obtain permission directly from the copyright holder. To view a copy of this licence, visit http://creativecommons.org/licenses/by/4.0/.

\section{References}

Ahn, J. M., Im, T. H., Lee, K. L., Jung, K. Y., Lee, J. W., Cheon, S. U., \& Park, I. H. (2014). A study on efficiency of water supply through conjunctive operation of reservoirs and multi-function weir in the Nakdong river. Journal of Korean Society Water Environmental, 30(2), 138-147. https://doi.org/10.15681/KSWE.2014.30.2.138.

Ahn, J. M., Kim, S., \& Kim, Y. S. (2019). Selection of priority management of rivers by assessing heavy metal pollution and ecological risk of surface sediments. Environmental Geochemistry and Health. https://doi.org/10.1007/s10653019-00284-9.

Alloway, B. J., Thornton, I., Smart, G. A., Sherlock, J. C., \& Quinn, M. J. (1988). Metal availability. The Science of the Total Environment, 75, 41-69. https://doi.org/10.1016/00489697(88)90159-3.

Bruland, K. W., Bertine, K., Koide, M., \& Golberg, E. D. (1974). History of metal pollution in southern California coastal zone. Environmental Science and Technology, 8(5), 425432. https://doi.org/10.1021/es60090a010.

CCME. (1995). Protocol for the derivation of canadian sediment quality guidelines for the protection of life (report CCME EPC-98E). Canada, Ottawa, https://www.ccme. $\mathrm{ca} /$ files/Resources/supporting scientific documents/pn 1176 e.pdf.

Chen, K., Jiao, J. J., Huang, J., \& Huang, R. (2007). Multivariate statistical evaluation of trace elements in groundwater in a coastal area in Shenzhen, China. Environmental Pollution, 147, 771-780. https://doi.org/10.1016/j.envpol.2006.09.002.

Dekov, V. M., Komy, Z., Araujo, F., Van Put, A., \& Van Grieken, R. (1997). Chemical composition of sediments, suspended matter, river water and ground water of the Nile (Aswan-Sohag traverse). The Science of the Total Environment, 201(3), 195-210. https://doi.org/10.1016/S0048-9697(97)84057-0.

Duodu, G. O., Goonetilleke, A., \& Ayoko, G. A. (2016). Comparison of pollution indices for the assessment of heavy metal in 
Brisbane River sediment. Environmental Pollution, 219, 10771091. https://doi.org/10.1016/j.envpol.2016.09.008.

Folk, R. L. (1980). Petrology of sedimentary rock. Texas: Hemphill Publishing Company Austin.

Folk, R. L., \& Ward, W. C. (1957). Brazos river bar [Texas]: A study in the significance of grain size parameter. Journal of Sedimentary Petrology, 27(1), 3-26. https://doi.org/10.1306 /74D70646-2B21-11D7-8648000102X1865D.

Ganugapenta, S., Nadimikeri, J., Chinnapolla, S. R. R. B., Ballari, L., Rajasekhar, M., Madiga, R., Nirmala, K., \& Tella, L. P. (2018). Assessment of heavy metal pollution from the sediment of Tupilipalem Coast, southeast coast of India. International Journal of Sediment Research, 33, 294-302. https://doi.org/10.1016/j.ijsec.2018.02.004.

GESAMP (1985). Cadmium, lead and tin in the marine environment, UN/FAO/UNESCO/WHO/WMO/IAEA/UNEP joint Group of Experts on the Scientific Aspects of Marine Pollution, GESAMP Report and Studies No.22.

Grant, A. (1990). Multivariate statistical analysis of sediment geochemistry. Marine Pollution Bulletin, 21(6), 297-299. https://doi.org/10.1016/0025-326X(90)90594-X.

Han, G. M., Hong, S. H., Shim, W. J., Ra, G. T., Kim, G. T., Ha, S. Y., Jang, M., \& Kim, G. B. (2016). Assessment of persistent organic and heavy metal contamination in Busan coast: Application of sediment quality index. Ocean and Polar Research, 38(3), 171-184. https://doi.org/10.4217 /OPR.2016.38.3.171.

Horowitz, A. J. (1991). A primer on sediment-trace element chemistry. Lewis publish, Chelsea, https://pdfs. semanticscholar.org/bar12/56aa9766c0d3e0b6ea73bb1 fa9561fbcf120.pdf.

Hyun, S., Lee, C. H., Lee, T., \& Choi, J. W. (2007). Anthropogenic contributions to heavy metal distributions in the surface sediments of Masan bay, Korea. Marine Pollution Bulletin, 54(7), 1059-1068. https://doi.org/10.1016/i. marpolbul.2007.02.013.

Jung, K. Y., Lee, K. L., Im, T. H., Lee, I. J., Kim, S., Han, K. Y., \& Ahn, J. M. (2016). Evaluation of water quality for the Nakdong river watershed using multivariate analysis. Environmental Technology and Innovation, 5, 67-82. https://doi.org/10.1016/j.eti.2015.12.001.

Kim, J. G., \& Jang, H. S. (2014). Evaluation of characteristics of particle composition and pollution of heavy metals for bottom sediments in Cheonsu bay, Korea-Comparison of the sediments environment of farming area and non-farming area. Journal of Korea Society of Marine Environment and Safety, 20(4), 358-371. https://doi.org/10.7837 /kosomes.2014.20.4.358.

Kim, D. H., \& Um, H. H. (2013). Estimation of the sediment pollution in coast of Gwangyang, Mokpo and Shinan, Korea. Journal of Korea Society of Marine Environment and Safety, 19(4), 303308. https://doi.org/10.7837/kossmes.2013.19.4.303.

Kim, J. Y., Eun, G. Y., Koh, Y. K., Youn, S. T., Oh, K. H., \& Kim, D. J. (2001). Sedimentary environments and geochemical characters of the core sediments near Naju-Yeongam area in the lower part of the Yeongsan river, Cheonnam, Korea. Journal of the Korean Earth Science Society, 22(4), 301-316.

Kim, M. J., Chang, T. S., Rhee, C. W., \& Jin, J. H. (2010). Feasibility assessment of a microtrac tri-laser diffraction particle size analyzer for use in sedimentary geology: A comparison of grain-size analysis with sieve-pipette method. Journal of the Geological Society of Korea, 46, 197-205.

Kim, S., Kim, J. E., Lee, K. C., Lee, K. Y., Jeon, H. L., Yu, J. J., Lee, I. J., \& Ahn, J. M. (2015a). Distribution and pollution of heavy metals in surface sediments from Nakdong river. Journal of Environmental Science International, 24(8), 969-980. https://doi.org/10.5322/JESI.2015.24.8.969.

Kim, S., Lee, G. Y., Kim, J. U., Lee, K. C., Ahn, J. M., Lee, I. J., Jung, K. Y., \& Im, T. H. (2015b). Vertical variation of sediment structure and geochemical characteristics of core sediment in Nakdong river midstream. Journal of Korea Society on Water Environment, 31(3), 304-312. https://doi. org/10.15681/KSWE.2015.31.3.304.

Kim, S., Lee, K. C., Kim, J. E., Jung, K. Y., Ahn, J. M., Kim, H. G., Lee, I. J., Shin, D. S., \& Yang, D. S. (2017). Change in geochemical characteristics of surface sediments in the Nakdong river main stream. Journal of Environmental Science International, 26(3), 311-324. https://doi. org/10.5322/JESI.2017.26.3.311.

Kim, S., Ahn, J. M., Kim, H. G., Kwon, H. G., Kim, G. H., Shin, D. S., \& Yang, D. S. (2018). The distribution characteristics of grain size and organic matters of surface sediments from the Nakdong-Goryeong mid-watershed. Journal of Environmental Science International, 27(6), 411-423. https://doi.org/10.5322/JESI.2018.27.5.281.

Lai, T. M., Lee, W., Hur, J., Kim, Y., Huh, I. A., Shin, H. S., \& Lee, J. H. (2013). Influence of sediment grain size and land use on the distributions of heavy metals in sediments of the Han River Basin in Korea and the assessment of anthropogenic pollution. Water, Air, and Soil Pollution, 224(7), 16091621. https://doi.org/10.1017/s11270-013-1609-y.

Lee, J. B., Hong, S. H., Kim, D. H., Huh, I. A., Huh, Y. J., Khan, J. B., Oh, D. Y., Kim, K. Y., Lee, Y. J., Lee, S. H., \& Shin, H. S. (2014). Measurement of metals in sediment of the GeumRiver and their correlation. Analytical Science \& Technology, 27(1), 11-24. https://doi.org/10.5806/AST.2014.27.1.11.

Md, S. I., Md, K. A., Mohammad, R., Md, H. A. M., \& Muhammad, K. I. (2015). Heavy metal pollution in surface sediment: A preliminary assessment of an urban river in a developing country. Ecological Indicators, 48, 282-291. https://doi.org/10.1016/j.ecolind.2014.08.016.

Ministry of Environment. (2012). Official test methods of water quality (report no. 2012-99). Sejong: Ministry of Environment.

Muller, G. (1979). Heavy metals in the sediment of the Rhinechanges seity. Umschau in Wissenschaft und Technik, 79, $778-783$.

NIER (2011). Baseline concentrations of heavy metals in river sediments in Korea (report no. TRKO201300007691). Inchun: National Institute Environmental Research.

NIER (2015). Sediment pollution evaluation standard of river and lake (published rulings 2015-687). Inchun: National Institute Environmental Research.

NIER (2017). Result on target water quality monitoring network operation of Nakdong River System in 2017 (report no. 111480000-0001481-14). Inchun: National Institute Environmental Research.

Oh, K. H., Kim, J. Y., Koh, Y. K., Youn, S. T., Shin, S. E., Park, B. Y., Moon, B. C., \& Kim, H. G. (2003). Geochemical characteristics and contamination of surface sediment in 
streams of Gwangju city. Journal of the Korean Earth Science Society, 24(4), 346-360.

Pandey, M., Tripathi, S., Pandey, A. K., \& Tripathi, B. D. (2014). Risk assessment of metal species in sediments of the river ganga. Catena, 122, 140-149. https://doi.org/10.1016/j. catena.2014.06.012.

Park, J. E., Kim, J. G., \& Ahn, S. Y. (2011). Distribution and source identification of PCDD/Fs and Co-PCBs in sediments from the Geum river. Korea Environmental Engineering Research, 33, 900-906. https://doi.org/10.4491 /KSEE.2011.33.12.900.

Ra, K. T., Kim, E. S., Kim, J. K., Lee, J. M., \& Kim, E. Y. (2013). Distribution and pollution assessment of trace metals in core sediments from the artificial lake Shihwa. Journal of Ocean Polar Research, 35(2), 69-83. https://doi.org/10.4217 /OPR.2013.35.2.069.

Sekabira, K., Oryem Origa, H., Basamba, T. A., Mutumba, G., \& Kakudidi, E. (2010). Assessment of heavy metal pollution in the urban stream sediments and its tributaries. International Journal of Environmental Science and Technology, 7(3), 435-446. https://doi.org/10.1007/BF03326153.

Shin, S. E., Youn, S. T., Koh, Y. K., \& Oh, K. H. (2015). The geochemical characteristics and environmental changes of surface sediment in Yeonsan River area. Journal of the Korean Geomorphological Association, 22(3), 31-42. https://doi.org/10.16968/JKGA.22.3.31.

Song, Y., Ji, J., Yang, Z., Yuan, X., Mao, C., Frost, R. L., \& Ayoko, G. A. (2011). Geochemical behavior assessment and apportionment of heavy metal contaminants in the bottom sediments of lower reach of Changjiang River. Catena, 85(1), 73-81. https://doi.org/10.1016/j.catena.2010.12.009.

Thornton, I. (1983). Applied environmental geochemistry. London: Academic Press.

Tomlinson, D. L., Wilson, J. G., Harris, C. R., \& Jeffrey, D. W. (1980). Problems in the assessment of heavy metals in estuaries and the formation pollution index. Helgoland Scientific Meeresunteruchung, 3(1-4), 566-575. https://doi. org/10.1007/BF02414780.

US EPA (1999). Protocol for developing sediment TMDL (report EPA 841-B-99-004). Washington: US EPA. https://purl. access.gpo.gov/GPO/LPS50983.

Yongming, H., Peixuana, D., Junji, C., \& Posmentier, E. S. (2006). Multivariate analysis of heavy metal contamination in urban dust of Yi'an, central China. Science of the Total Environment, 355, 176-186.

Zhang, J. H., \& Liu, C. L. (2002). Riverine composition and estuarine geochemistry of particle metals in ChinaWeathering features, anthropogenic impact and chemical fluxes. Estuarine, Coastal and Shelf Science, 54(6), 10511070. https://doi.org/10.1006/ecss.2001.0879.

Publisher's note Springer Nature remains neutral with regard to jurisdictional claims in published maps and institutional affiliations. 